\title{
Study of Complications of Traditional Treatment. Member Fractures
}

\section{Louis Traore ${ }^{1}$, Laye Toure ${ }^{2}$, Moussa Sidibe ${ }^{1}$, Mamadou Diallo² $^{2}$ Aboul Kadri Moussa ${ }^{1}$, Mamadou Bassirou Traore ${ }^{1}$, Tiéman Coulibaly ${ }^{1}$}

${ }^{1}$ Service de Chirurgie orthopédique et traumatologique, CHU Gabriel Touré, Bamako, Mali

${ }^{2}$ Service de Chirurgie orthopédique et traumatologique Hopital Regional de Sikasso, Bamako, Mali

Email: trlouis01yahoo.fr

How to cite this paper: Traore, L., Toure, L., Sidibe, M., Diallo, M., Moussa, A.K., Traore, M.B. and Coulibaly, T. (2020) Study of Complications of Traditional Treatment. Member Fractures. Surgical Science, 11, 289-297. https://doi.org/10.4236/ss.2020.1110031

Received: April 19, 2020

Accepted: October 25, 2020

Published: October 28, 2020

Copyright $\odot 2020$ by author(s) and Scientific Research Publishing Inc. This work is licensed under the Creative Commons Attribution-NonCommercial International License (CC BY-NC 4.0). http://creativecommons.org/licenses/by-nc/4.0/ (c) (i) (5) Open Access

\begin{abstract}
Introduction: Since the times of our ancestors, traditional medicine has existed to cure all diseases [1]. The objective of this study was to assess the complications of traditional fracture treatment. Patients and Methods: This was a prospective study extending from January 01, 2018 to June 30, 2018, duration of six months. It concerned patients who had traditionally been treated beforehand for traumas with bone lesion in a traditional therapist and who had developed a complication, the definitive management of which was made in the department. Results: This study involved 102 patients, including 71 men $(69.6 \%)$, with a sex ratio of 2.2 .33 patients or $32.4 \%$ were under 15 years old. The average of our patients' age was 29.61 years with extremes of 2 and 89 years. Pupils/students (44 pupils and 5 students) were the most represented with 49 cases or $48.1 \%$ of the cases. The majority of patients (59.8\% of cases) were educated or had a basic level. The majority of patients (36.3\%) came as motif for a painful swelling. Gangrene was the most common complication with 37 cases or $36.3 \%$ of cases. Conclusion: At the end of our study, we have noticed that the traditional preliminary treatment of fractures was based mainly on trial and error. Practicing with inadequate means and measures without respecting the anatomical structures, is a real source of disabling handicaps. We have recorded 38, among the 102 patients who came for a complication of traditional treatment: that is $45.2 \%$ amputation, which is deplorable.
\end{abstract}

\section{Keywords}

Fracture Complications, Traditional Treatments 


\section{Introduction}

Since the time of our ancestors, traditional medicine has existed to cure all diseases [1]. Traditional treatment in orthopedic trauma is very widespread (60.7\%) [2] in Mali and retains an important place alongside modern medicine [2].

But what is serious and which jeopardizes the functional and vital prognosis of patients is that this medicine is practiced without doctors, which exposes patients to many iatrogenic complications.

The objective of this study is to assess the complications caused by the traditional treatment of fractures in the orthopedic and trauma surgery department of the C.H.U. Gabriel TOURE.

\section{Patients and Methods}

It was a 6 months prospective study, extending from January 01st, 2018 to June 30th, 2018. It focused on patients who were traditionally treated by a traditional healer for traumatic fracture of the limbs with complicated consequences and whose management was done in the orthopedic and trauma surgery department of the CHU Gabriel TOURE.

All trauma patients with one or more bone lesions who had undergone treatment were included. traditional and complicating after this treatment; not included all trauma victims without bone lesion who underwent traditional treatment, all trauma patients who underwent treatment traditional but not having developed a complication, all the traumatized people not having undergone traditional treatment, the patients having been treated outside the study period who were not taken care of in the orthopedic and trauma surgery department of the Gabriel TOURE hospital.

Data collection was done from an individual questionnaire sheet. They were collected in the medical file, the registers of outpatient checking, surgery reports and hospitalizations.

were collected sex, age, profession, level of education, mode of admission, reason for consultation, types of complications, etiology, member concerned, The limb segment, the bone involved, the type of fracture, site of the fracture on the bone, the type of traditional treatment, the duration of the traditional treatment, additional examination, treatment received in hospital, type of surgery.

The traditional types were: incantations, immobilizations bytraditional wooden splints for the upper limb and for the lower limb (Figure 1) and sometimes traction of the lowerlimb on a traditional traction machine from Dogon country (Figure 2).

\section{Results (Table 1 and Figure 3)}

This study concerned 102 Patients: Male was predominant with 71 cases or $69.6 \%$ of the cases with a sex ratio of 2.29 in favor of men. 33 patients or $32.4 \%$ were under 15 years old; the average age was 29.61 years with extremes of 2 and 


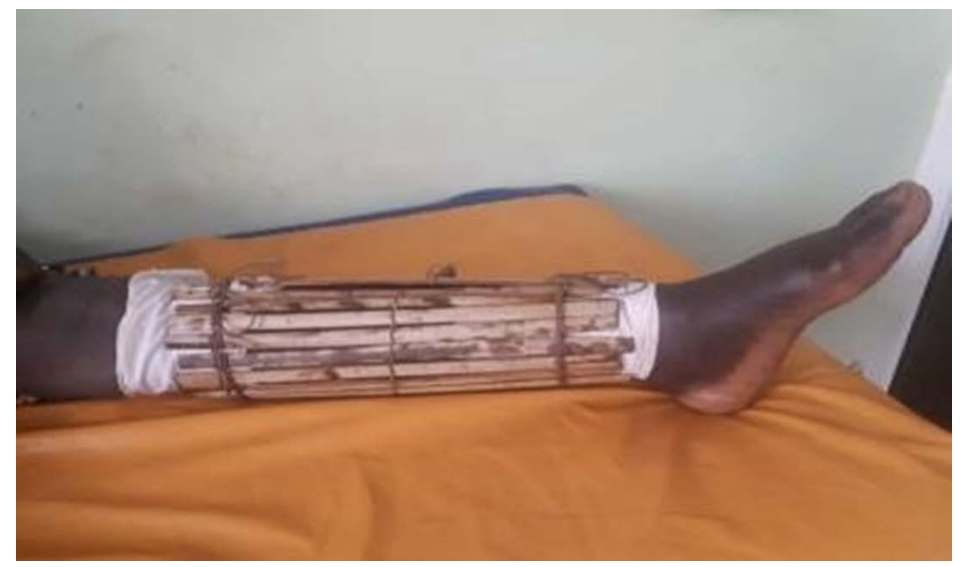

Figure 1. Immobilizations bytraditional orthopedics wooden splints for the lower (limb. (image of the orthopedic traumatology departement of CHU GABRIEL TOURE).

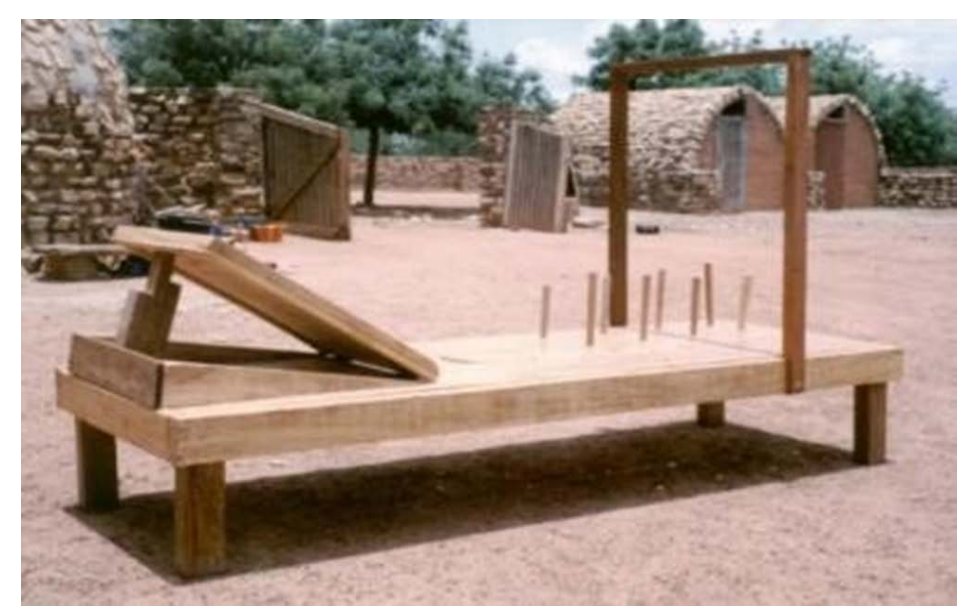

Figure 2. Table in dogon's country (20).

Table 1. Distribution of patients by complication.

\begin{tabular}{ccc}
\hline Complications & Number of samples & Percentage \\
\hline Vicious cal & 14 & 13.7 \\
Ankylosis & 2 & 2.0 \\
Volkman syndrome & 7 & 6.9 \\
Osteoarthritis & 4 & 3.9 \\
Lodge syndrome & 18 & 17.6 \\
Necrotic wound & 11 & 10.8 \\
Gangrene & 37 & 36.3 \\
Others & 9 & 8.8 \\
Total & 102, & 100.0 \\
\hline
\end{tabular}

${ }^{*}$ Osteitis (2), pseudarthrosis (2), pseudarthrosis, pain, pain + impotence, necrotizing facitis, osteomyelitis of the right thigh. 


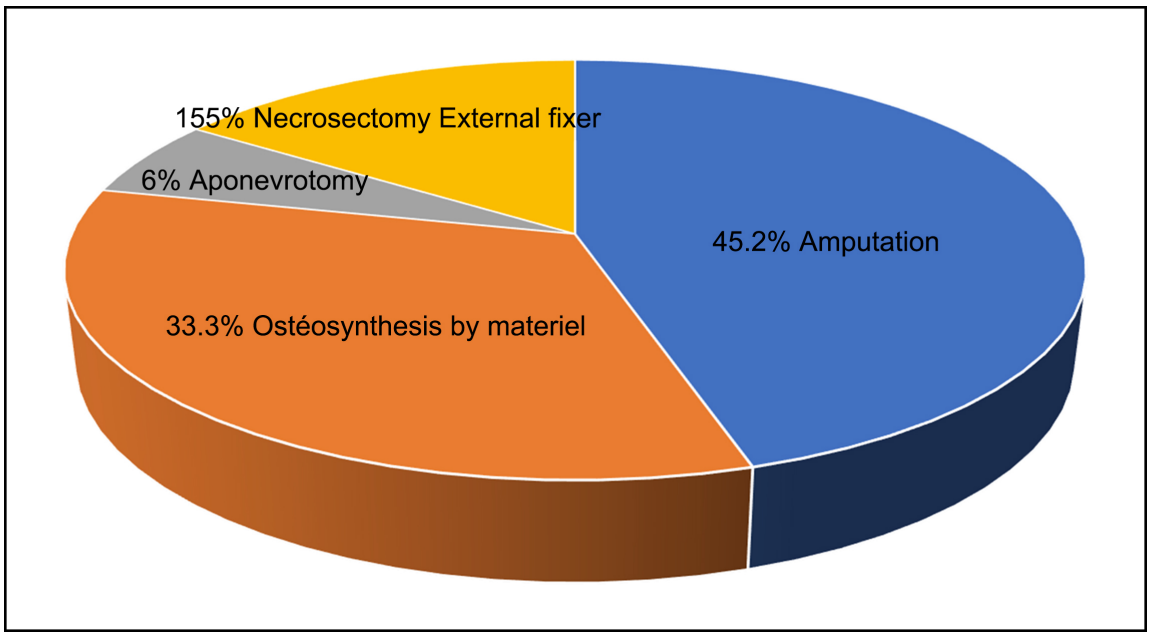

Figure 3. Distribution of patients by type of surgery.

89 years. Pupils/students (44 pupils and 5 students) were the most represented with 49 cases or $48.1 \%$ of cases.

The majorities of patients, i.e. $59.8 \%$ of cases, were educated or had a basic level; 85 patients or $83.3 \%$ consulted by their own decision or by parents.

The majority of patients (36.3\%) consulted for a painful swelling

Gangrene was the most represented complication with 37 cases or $36.3 \%$ of cases.

Accidents in the home constituted the main etiology of trauma with $61.8 \%$ of cases. The lower limb was the most affected, $58.8 \%$ of the cases. Both sides had the same rate reached, $50 \%$ each.

The forearm was the most affected limb segment with 21 cases or $20.6 \%$. The femur was the most affected bone, accounting for $23.5 \%$ of the cases. The complex fracture represented the majority of the type of fracture with 52 cases or $51.0 \%$. The diaphysis was the most affected site of the fracture, $59.8 \%$ of the cases. The complex fracture represented the majority of the type of fracture with 52 cases either $51.0 \%$. Massage + Splint + Incantation was the most used traditional type of treatment with 59 cases or $57.8 \%$ of cases.

In $37.3 \%$ of cases, or 38 patients, the duration of traditional treatment is between 7 and 14 days with an average duration of $40.65 \pm 70.884$, the minimum duration of which was 1 day and maximum of 1 year. Receivedan x-ray, 100\% of the cases. Surgical treatment was frequently used in hospital in $82.4 \%$ of cases

\section{Discussion}

\subsection{Sociodemographicdata}

Patients aged 0 to 15 years were the most represented with $32.4 \%$ of cases, this could be explained by the fact of a higher exposure of this age group. The high frequency in this age group is also noted in the work of:

TOGO S. [3] in his thesis on acute ischemic complications following the traditional treatment of trauma of the limbs in the orthopedic and trauma surgery 
departments of Kati hospital and Gabriel Touré hospital, found 62, 86\% of cases in 2007

AYITE A. et Coll. [4] who found in their study on the traditional treatment of fractures in Niger, $81.58 \%$ of children under 15 years old.

MIEREY J. C. [5] who recorded in his thesis on amputations: members following the traditional treatment of fractures in the trauma orthopedic surgery department of the Gabriel Toure hospital in 2005, 42.22\% of patients under 15 years.

Bamba I. et al. [6] who recorded during their study on gas gangrene: with regard to an unusual etiology, $46.66 \%$ of patients under 15 years old.

Togora M. [7], who in his thesis on trauma traditionally treated beforehand in the orthopedic and trauma surgery department of the C. H. Gabriel Toure in 2011 , recorded $35.16 \%$ of patients under 15 years old.

The male prevalence during our study and in our sample was $69.6 \%$ of cases with a sex ratio of 2.29 in favor of men; which agrees with the literature: TOGORA M. [7]; FANE G. [8]; SOUNA B. S. and Coll [9]; SOUMAH M. T. et al. [10] and TOGO S. [3] with 59.34\% respectively; $72.9 \%$; $77.85 \% ; 78.26 \%$ and $77.14 \%$ of the cases made the same observations. This could be explained by the great mobility of male subjects, hence their exposure to trauma.

Pupils/students (23/5) with $27.5 \%$ of the cases were the most represented. This would be linked to the fact that they constitute one of the most active and vulnerable layer of the population.

DIAKITE S. K. et al. [11] reported $44.44 \%$ of pupils and students.

TOGORA M. [7] reported $41.76 \%$ of pupils and students.

SOUMAH M. T. and Coll. [10] found $34.78 \%$ of pupils.

TOGO S. [3] recorded in his thesis $45.71 \%$ of pupils and students.

The majority of patients with 61 cases or $59.8 \%$ of cases were from Bamako. This is explained either by ignorance or a refusal of modern health structures or a multiplication of traditional therapists in the city.

Thus, our results are opposite to those of BAMBA I. et al. [6]; TOGORA M. [7]; and TOGO S. [3] who respectively found $60 \%$ of the cases; $42.86 \%$ and $51.43 \%$ of cases. On the other hand, our results can be compared to that of FANE G. [8] who recorded $52 \%$ of the cases originating from Bamako.

Most of the patients with $59.8 \%$ of the cases or 61 cases were educated. This could be explained by a lack of patient confidence in modern health facilities; unlike the work of MIEREY J. C. [5] who found in his study on limb amputations following the traditional treatment of fractures $40 \%$ of out-of-school patients.

\subsection{Descriptive Results}

85 patients or $83.3 \%$ of cases were in the hospital on their own decision; but 17 patients or $16.6 \%$ of cases were referred to a health facility, which could be explained simply by the worsening of the lesion which prompts patients to consult 
themselves?

We have not recorded any patients referred by traditional healers. FANE G. [8] in his thesis on the management of complications from traditional elbow trauma, recorded $93.8 \%$ (or 45 cases) of patients who consulted themselves at I $\mathrm{H} \mathrm{K}$ after a stay with the healer traditional. TOGORA M. [7] registered 58 patients, or $63.7 \%$ of the cases who were in hospital on their own initiative.

Accidents in the home were the most represented with $61.8 \%$ of the cases. This rate could be explained by the fact that children under the age of 15 are the group most affected by accidents in the home.

DIAKITE A. G. [11]; MIEREY J. C. [5] and TOGO S. [3] found $44.44 \%$ respectively; $46.2 \%$ and $31.43 \%$ of domestic accident cases.

Pain associated with swelling represented the majority of the reasons for consultation with $36.3 \%$ of cases; which would be explained by the fact that pain is the first symptom in front of any case of trauma, as well as the swelling which follows an inflammation. In his thesis TOGARA M. found pain as the main reason for consultation in $80.2 \%$ of cases. The forearm was the most affected limb segment with $20.6 \%$ of the cases.

This would be explained by the often indirect mechanism of the accident of domestic life and also that the forearm constitutes the part most exposed to trauma.

DIARRA E. [12] found in his study a predominance of the leg with $38.5 \%$ of cases

MIEREY J. C. [5] noted $33.33 \%$ of leg trauma;

GARBA E. S. and DESHIP [13] in Nigeria found the majority of amputations in the leg following traditional treatment with $26.87 \%$ of cases.

DIAKITE A. G. [11] had during his study $29.3 \%$ trauma to the femur.

TOGO S. [3] noted in his thesis 13 cases or $37.14 \%$ of leg trauma.

Massage combined with an incantation and a traditional splint constituted the most used traditional type of prior treatment with $57.8 \%$ of the cases. As an explanation, we can say that it is a heritage that is transmitted from father to son whose traditional healers do not realize harmful effects that can be secondary to massage and especially to the too tight splint. Our results are similar with regard to the type of traditional prior treatment used, as those of TOGO S. [3] who recorded in his thesis $72.22 \%$ of the cases of trauma which were treated by splint associated with an overly tight bandage. TOGORA M. [7] meanwhile recorded in his thesis $83.5 \%$ of massage cases coming from traditional healers.

In $37.3 \%$ of cases, or 38 patients, the duration of traditional treatment, which reflects the time taken to install the complication, is between 7 and 14 days, i.e. a maximum of 2 weeks after prior traditional treatment. This short delay could be explained by the fact that the treatment methods used by traditional healers cause complications after their institution and for a short duration.

TOGORA M. [7] recorded $38.46 \%$ of the time it took to set up the complication after the traditional prior treatment, which was 48 hours. Gangrene was the 
most common complication with $36.3 \%$ of the cases or 37 cases. This complication is related to the type of traditional pretreatment that has been used the most, namely massage and the traditional too tight splint. The compartment syndrome comes in second position among the complication recorded that is $17.6 \%$ of the cases. This could be explained by the same reason which is the treatment that the traditional therapists used, that is to say the traditional too tight splint. Our results are different from those of DIAKITE C. et al. [11] who did not find any case of complications after traditional treatment, notably fever, edema, suppuration, inflammation, pain, visible alterations, stiffness, delay in consolidation or scarring. out of a series of 101 patients examined ( 9 exposed and or complicated fractures, 44 simple fractures, 48 dislocations and sprains).

Surgical treatment was mainly used in hospital in $82.4 \%$ of the cases, ie in 84 patients; which would be related to the most common complication, namely gangrene $(36.3 \%)$, therefore amputation was the most used surgical treatment in $45.2 \%$ (38 patients). This can be explained by the frequency of massage and too tight splint as traditional treatment previously used.

The complex fracture in $51.0 \%$ of cases represented the majority of the type of fracture. Our results are different from those of:

- TOGO S. [3] who found 51, 43\% of cases in his study.

- AYITE A. et al. [4] found $84.42 \%$ of closed fractures.

- BAMBA I. et al. [6] reported $80 \%$ of closed fractures.

- THIAM S. M. [14] had $73.70 \%$ of simple initial fractures.

\subsection{Analytical Results}

The distribution of the reason for consultation according to the type of treatment received at the hospital is significant because the prevalence $\mathrm{p}<10^{-3}$ (Fisher's exact test) is less than 0.05 ;

The distribution of the nature of the accident according to the course of treatment received at the hospital is not significant since the prevalence $\mathrm{p}=$ 0.126 (Fisher's exact test) is greater than 0.05 .

The distribution of traditional prior treatment according to the type of complication is significant because the prevalence $\mathrm{p}=0.031$ (Fisher's exact test) is less than 0.05

The distribution of the type of fracture according to the type of complication is significant because the prevalence $\mathrm{p}=0.034$ (Fisher's exact test) is less than 0.05 .

The distribution of the origin of the patients according to the type of complication is not significant because the prevalence $\mathrm{p}=0.225$ (Fisher's exact test) is greater than 0.05 .

The distribution of the time to installation of the complication after traditional prior treatment according to the course of treatment received in hospital is significant because the prevalence $\mathrm{p}=0.045$ (Fisher's exact test) is less than 0.05 .

The distribution of the type of treatment received in hospital according to the 
type of complication is significant because the prevalence $\mathrm{p}<103$ (Fisher's exact test) is less than 0.05 .

The distribution of the complication according to the outcome of treatment in the hospital is not significant because the prevalence $\mathrm{p}=0.724$ (Fisher's exact test) is greater than 0.05

The distribution of treatment for the complication according to the outcome of treatment in the hospital is not significant since the prevalence $p=1000$ (Fisher's exact test) is greater than 0.05 .

We recorded 4 cases or $3.9 \%$ of deaths during our study, unlike TOGORA M. [7] recorded no death during his thesis but TOGO S. [3] who during his thesis noted a case of death in a tetanus table; and to MIEREY J. C. [5] who had one case of death in a tetanus table on 45 cases of complication, ie $2.2 \%$ of the cases; also, BAMBA I. et al. [6] found one death in 15 cases of gangrene, or $6.6 \%$ of the cases.

\section{Conclusions}

At the end of our study on the complications of traditional fracture treatment; we have noticed that:

- The traditional prior treatment of fractures, based mainly on trial and error, practiced with inadequate means and measures without respect for the anatomical structures, is a real source of disabling handicaps. Of the 102 patients who came for a complication of traditional treatment, we recorded 38 patients that are $45.2 \%$ amputation, which is deplorable. Children under the age of 15 are the first victims of traditional prior treatment for trauma (33 patients, or $32.4 \%$ of cases).

- The orthopedic and trauma surgery ward of the C.H.U. Gabriel TOURE obtains very good results in the care of patients previously treated traditionally for fracture (complete healing in 98 patients or $\mathbf{9 6 . 1 \%}$ of cases).

\section{Conflicts of Interest}

The authors declare no conflicts of interest regarding the publication of this paper.

\section{References}

[1] Youmachev, G. (1977) Traumatology and Orthopedics. MIR, 3rd.

[2] Diallo, M. (1994) Elbow Trauma. USTTB, Bamako.

[3] Togo, S. (2007) Acute Ischemic Complications Following Traditional Treatment of Limb Trauma. USTTB, Bamako.

[4] Ayite, A., Minyoarehe, N., Mazoum, I. and Sacko, A. (1995) Traditional Treatment of Fractures in Niger. Med Afr Noire, 641.

[5] Mierey, J.C. (2005) Limb Amputations Following the Traditional Treatment of Fractures. USTTB, Bamako.

[6] Bamba, I., Agoh, S., Toure, S., Bana, V.G., Lambin, Y., et al. Les gangrènes gazeuses: 
À propos d'étiologie insolite. Vol. 118, 37.

[7] Togora, M. (2011) Epidemiological and Clinical Study of Trauma Traditionally Treated Beforehand. USTTB, Bamako.

[8] Fané, G. (2006) Management of Complications in the tration of Elbow Injuries [Thèse de Médecine]. USTTB, Bamako.

[9] Souna, B., Sacko, A. and Yacouba, I. (2004) The Limits of the Traditional Treatment of Limb Fractures.1 st SOMACOT Congress, 54.

[10] Soumah, M., Camara, T., Kante, T., Kebe, M. and Soumah, I. (2004) Problem of the Management of Fractures Treated in Traditional Medicine. 1st SOMACOT Congress, 55.

[11] Diakite, A. (2002) Complication and Sequelae of the Traditional Treatment of Fractures of the Lower Limbs. USTTB, Bamako.

[12] Diarra, E. (2001) Epidemiological and clinical Aspects of Amputations. USTTB, Bamako.

[13] Garba, E.S. and Deshi, P. Traditional Bone Setting a Risk Factor in Limb Amputation. 75 .

[14] Thiam, S.M. (1997) Aspects, Treatment and Evolution of Complications of Traditional Fracture Treatment. USTTB, Bamako. 